\title{
Recent trends in Advanced Functional Semiconducting Materials (selected papers from the IMRC2019, Cancun, Mexico, 18-23 August 2019, Symposium on Advances in Functional Semiconducting Materials)
}

\author{
Subramaniam Velumani ${ }^{1}$
}

Published online: 21 April 2020

C) Springer Science+Business Media, LLC, part of Springer Nature 2020

\section{Editorial}

Recent Advances in Functional Semiconducting Materials (AFSM) is of interest for both fundamental research and industrial applications. In this special issue, selected papers from the 18th International Materials Research Congress (IMRC2019) held in Cancun, Mexico during 18-23 August 2019 are published after subjecting it to the journal's high standard of rigorous peer-review process. IMRC was jointly organized by Sociedad Mexicana de Materials (SMM), Mexico, and the Materials Research Society (MRS), USA. Among the 36 different symposia organized, AFSM was organized consecutively for the 12th year and in 2019, 7 invited papers, 32 oral papers and 146 posters were presented. All the researchers have not only delivered presentations but also remained through the conference and actively participated to augment the quality of the scientific program.

The goal of this annual symposium is to provide discussions between researchers working on a wide range of semiconducting materials that have similar properties and applications; or have been characterized by similar techniques. This symposium served the purpose of those researchers who sought both a national and international meeting that covered key issues such as growth, characterization, theoretical evaluations, device applications and other

specific problems encountered in semiconductors. All the participants used this as a platform for disseminating recent research results from their respective laboratories gaining an excellent opportunity to interact with experts and industrialists around the world to discuss and kickoff collaboration at the national and international level. This year, the main focus was on different topics especially the role of semiconducting materials either in bulk or thin film; in photovoltaic, photocatalysis, microelectronics, novel display materials, electronic packaging materials, etc.

It is my great privilege to express my sincere thanks to all the contributing authors, the reviewers of the journal and especially to the Editor-in-Chief Professor S. Kasap and all associates from the Springer; their coordinated work and timely alerts made this special issue a reality. I would like to extend my deepest appreciation to the organizing committee and volunteers who have made this symposium successful. Special thanks are due to my co-organizers Dr. Maria de Luz Olvera, CINVESTAV and Dr David Zubia, University of Texas, USA, and members of the international Scientific Advisory committee.

Publisher's Note Springer Nature remains neutral with regard to jurisdictional claims in published maps and institutional affiliations.

Subramaniam Velumani

velu@cinvestav.mx

1 Department of Electrical Engineering (SEES),

Centro de Investigación Y de Estudios Avanzados del

I.P.N.(CINVESTAV), Mexico City, Mexico 